\title{
Reliability-Centred Maintenance for Wind Turbines Based on Statistical Analysis and Practical Experience
}

\author{
Katharina Fischer, Member, IEEE, Francois Besnard, Graduate Member, IEEE, \\ and Lina Bertling, Senior Member, IEEE
}

\begin{abstract}
The concept of Reliability-Centred Maintenance (RCM) is applied to the two wind turbine models Vestas V44-600kW and V90-2MW. The executing RCM workgroup includes an owner and operator of the analyzed wind turbines, a maintenance service provider, a provider of condition-monitoring services and wind-turbine component supplier as well as researchers at academia. Combining the results of failure statistics and assessment of expert judgement, the analysis is focused on the most critical subsystems with respect to failure frequencies and consequences: the gearbox, the generator, the electrical system and the hydraulic system. The study provides the most relevant functional failures, reveals their causes and underlying mechanisms and identifies remedial measures to prevent either the failure itself or critical secondary damage. The study forms the basis for development of quantitative models for maintenance strategy selection and optimization, but may also provide a feedback of field experience for further improvement of wind-turbine design.
\end{abstract}

Index Terms--Reliability, availability, maintenance, wind energy, wind turbines, RCM, FMEA, failure

\section{INTRODUCTION}

$\mathrm{W}$ IND power technology has undergone an immense growth during the past decades, both with respect to turbine size and to worldwide installed capacity. As one of the key technologies for sustainable power generation, ambitious goals have been set for its continued development. A $2009 \mathrm{EU}$ Directive has set a target share from renewable energy of $20 \%$ for the EU by 2020. From a rated capacity of $84 \mathrm{GW}$ installed in the EU end of 2010, the baseline scenario of the European Wind Energy Association targets a capacity of $230 \mathrm{GW}$ by end of 2020, including $40 \mathrm{GW}$ of offshore wind power [1-2].

The cost for operations and maintenance (O\&M) of wind turbines, required to ensure their technical availability, presently constitutes a considerable portion of the life-cycle cost (LCC) and thus of the cost of wind energy: approximately $20-30 \%$ in onshore installations [3], up to $30 \%$ of the - considerably higher - LCC in offshore installations [4]. In order to make wind power cost-competitive with conventional generation technology even in offshore and remote onshore

This work was funded by the Research Foundation of Göteborg Energi, Gothenburg.

K. Fischer, F. Besnard and L. Bertling are with the Division of Electric Power Engineering, Department of Energy and Environment, Chalmers University of Technology, 41296 Gothenburg, Sweden. (e-mail: Katharina.Fischer@chalmers.se). locations, key factors are improvements in wind turbine design for enhanced inherent reliability, but also systematic solutions for maintenance management. Research has shown that the present maintenance of both on- and offshore installations is not optimized. It has revealed large potential savings by optimizing maintenance decisions over the lifetime to reduce the total cost (a) for maintenance activities and component failure, and (b) costs due to production losses, especially for large offshore wind parks [5-10].

In the present paper, the proven concept of ReliabilityCentred Maintenance (RCM) is applied to wind turbines. The paper is structured in the following way: In Section II, the relevance of RCM in the context of data-based maintenance management and the implemented analysis procedure are explained and placed in the context of related scientific work. Section III provides a description of the two analysed wind turbine models. For the subsystems selected for in-depth analysis in Section IV, Section V presents the results of the RCM study, giving particular emphasis on the discussion of the technical failure causes and suitable preventive measures. The central findings are summarized together with the identified key challenges for achieving improved reliability, availability and profitability of wind turbines in the conclusions in Section VI.

\section{Methodology AND Related Work}

The work presented here is part of a combined approach that aims at achieving cost-effective maintenance for wind power plants by means of data-based methods: ReliabilityCentred Asset Maintenance (RCAM) merges the proven systematic approach of RCM, explained e.g. in [11-12], with quantitative maintenance optimization techniques (described e.g. by [13-14]). While sole RCM as a qualitative method is limited in assessing the cost-effectiveness of different maintenance strategies, mathematical maintenance optimization techniques alone do not ensure that the maintenance efforts address the most relevant components and failures. By combining these two approaches, the RCAM method, which was originally developed for the application to electric power distribution systems [15], provides a promising framework also for the maintenance strategy selection and optimization of wind turbines .

The RCM analysis presented here is an essential part in the implementation of RCAM. Its purpose in the context of RCAM is, by means of a Failure Mode and Effect Analysis 
(FMEA), to reveal the components, the failure modes as well as the major underlying failure causes that are most relevant for the system reliability and availability, and to identify suitable preventive measures. In this way, the RCM study forms the basis of RCAM; it ensures to focus the subsequent development and application of mathematical models on the practically relevant items and failures. The efficiency of limiting the scope of the RCM study to the most relevant subsystems and failures is illustrated in Fig. 1. Summarizing failure data from over 750 wind turbines in Sweden in the period 1989-2005, it reveals that about $75 \%$ of the annual downtime are caused by only $15 \%$ of the failures. A similar result has been obtained from wind-turbine failure data from the German WMEP program as presented in [16].

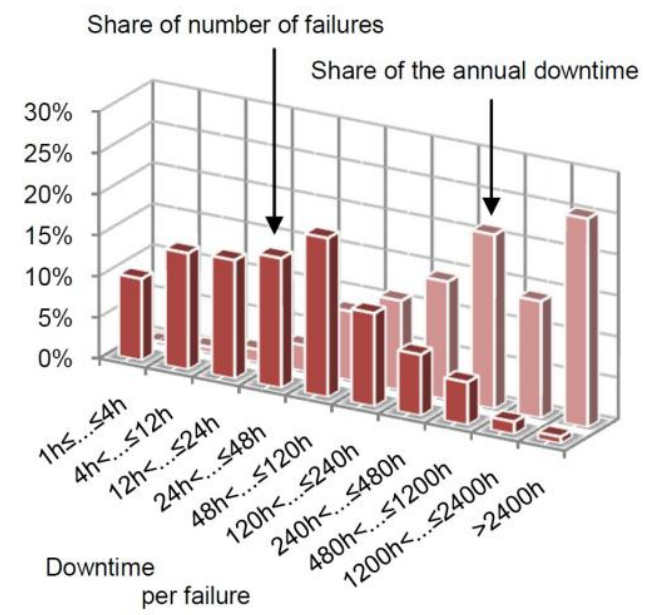

Fig. 1. Distribution of failures over resulting downtime vs. their share of the annual downtime: $75 \%$ of the annual downtime are caused by only $15 \%$ of the failures (Data source: [17])

Placing the presented study in the context of related work, a first application of RCM to an early-generation wind turbine for the purpose of maintenance strategy selection was described in 1987 by Quinlan [18]. Andrawus [19] and Bellens and Chemweno [20] carried out FMEA for a $600 \mathrm{~kW}$ turbine and a specific gearbox, respectively, as basis for quantitative maintenance strategy assessment, thus within an approach similar to RCAM. While Andrawus [19] provides a comprehensive compilation of failure modes and causes, no assessment of their relevance is provided. Chemweno [20] present rankings of gearbox-specific failure modes based on both Risk Priority Numbers and a life-cost based FMEA, but do not consider failure causes. In turn, Faulstich et al. [21] provide, based on statistical analysis of a large and diverse wind turbine population, the distribution of generic failure causes for a variety of components, however, without considering failure modes or underlying failure mechanisms. Alewine and Chen [22] discuss common failure modes and causes in wind-turbine generators based on experiences from over 800 repaired, refurbished or remanufactured generators, including a statistical review of their frequency. Finally, design-stage FMEA using generic failure modes and causes has been applied to an exemplary $2 \mathrm{MW}$ turbine within the
RELIAWIND project for comparison of different drive-train and generator concepts by Tavner et al. [23-24].

In this context, the present work is unique with respect to the statistics and experience-based focus on the most relevant subsystems and failure modes, the detailed discussion of the technical causes of failure, and the proposal of suitable preventive measures. The merge of practical experience and theoretical expertise realized in the described RCM workgroup is considered vital for the development of decision-support tools for wind-turbine O\&M and an important strength of the present work.

The RCM analysis presented here follows the methodology of a study described in [25] and the guideline given in [12]. The implemented limited-scope RCM analysis has covered the following steps:

(a) system selection and definition

(b) identification of system functions and functional failures

(c) selection of critical items

(d) data collection and analysis

(e) failure modes, effects, and criticality analysis (FMECA) including failure causes and mechanisms of the dominant failure modes

(f) identification of applicable maintenance actions

The consequences of failure have been assessed for the four criteria:

1. Safety of personnel

2. Environmental impact (in a wind turbine e.g. discharge of oil or glycol),

3. Production availability (i.e. the impact on electricity generation),

4. Material loss (including primary damage to the component itself, but also secondary damage to other parts of the system)

The determination of maintenance intervals and the comparative analysis of preventive maintenance measures by means of mathematical models are subject of subsequent work and not part in this paper.

A short description of the methodology of this study together with a tabular compilation of selected results has been published in [26]. The present article provides significant additional value with respect to the underlying statistical analysis, to the number of subsystems discussed and in particular to the depth of discussion.

\section{SYSTEM DESCRIPTION}

In the following, the two wind turbine models V44-600kW and V90-2MW that are subject of the RCM analysis are described together with their system-level functions and functional failures of interest in this context. The parallel analysis of the two turbines has been chosen to account for the differing reliability characteristics of turbines originating from different generations of technology (see e.g. [21, 27]), but also for the potentially different applicable preventive maintenance measures. It is important to note that the turbines have been selected for analysis not due to any abnormal occurrence of failures but due to their relevance for the project partners and 
to the available experience with O\&M of these turbines in the RCM workgroup.

It should be noted that there is usually some variance in design even between wind turbines of the same model. It is common practice that OEMs have several sub-suppliers for major components like e.g. the gearbox. This applies also to the systems analysed here. In addition, small changes in design can have been implemented over the years of production, as it is explicitly stated for the V90-2MW in [28].

\section{A. V44-600kW wind turbine}

The Vestas V44-600kW, launched in 1996, is an upwind turbine with three blades and an electrically driven yaw system. Its rotor has a diameter of $44 \mathrm{~m}$, a weight of $8.4 \mathrm{t}$ and a rated rotational speed of $28 \mathrm{rpm}$. A hydraulically actuated pitch system is used for speed control, optimization of power production, for start-up and for aerodynamic braking of the turbine. Additional breaking functionality is provided by a disc brake located on the high-speed side of the gearbox.

The structure of the V44-600kW system is shown in Fig. 2. During operation, the main shaft transmits the mechanical power from the rotor to the gearbox, which has either a combined planetary-parallel design or, as in case of the early V44 turbines analysed in this study, a parallel-shaft design. The gearbox and the generator are connected with a Cardan shaft. The generator is an asynchronous 4-pole generator with integrated electronically controllable resistance of the wound rotor (so-called OptiSlip technology, see Fig. 2), which requires neither brushes nor slip rings. The variability of the rotor resistance is provided by the Rotor Current Control unit (RCC) which is bolted to the non-drive end of the generator rotor and thus permanently rotates during wind turbine operation. It consists of a micro-processor unit to which the control signal is optically transmitted, of a power electronics unit and a resistor bundle. As shown in Fig. 2, the rotor resistance is varied in the way that the resistor bundle is shortcircuited at varying frequency by means of an IGBT in the power electronics unit. This OptiSpeed technology allows the rotational speed of the generator to vary between $1500 \mathrm{rpm}$ (idling) and $1650 \mathrm{rpm}$.

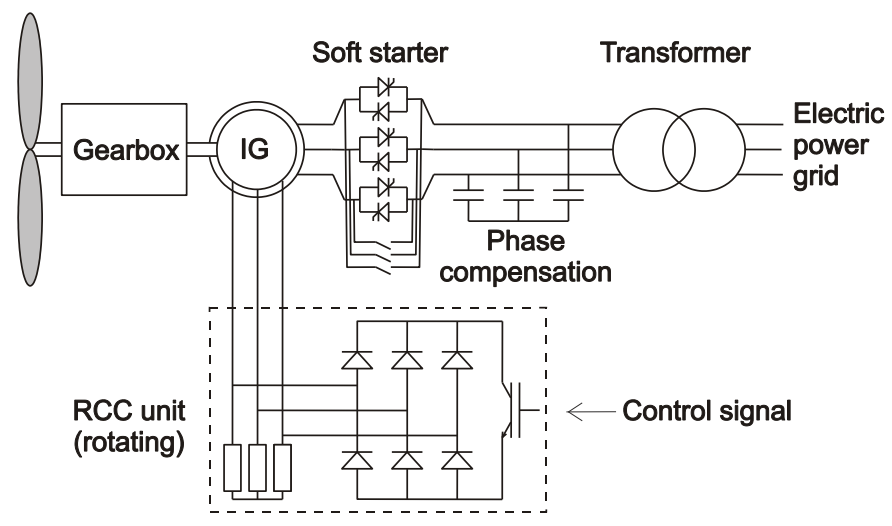

Fig. 2. Structure of the V44-600kW system with wound-rotor asynchronous generator and "OptiSlip" technology for rotor-current control
The generator stator is connected to the electric power grid through a thyristor unit, also called "soft starter". This limits the cut-in current of the asynchronous generator during connection to the grid and smoothly reduces the current to zero during disconnection from the grid. The reactive power required by the generator is partially provided by a capacitor bundle at the bottom of the tower, the power factor correction or phase compensation unit.

The main function of the V44 system, and the only one being of relevance in the scope of this study, is the conversion of kinetic wind energy to electric energy, which is provided to the electric power grid. More specifically, the system function is to provide up to $600 \mathrm{~kW}$ electric power at $690 \mathrm{~V}$ and $50 \mathrm{~Hz}$ to the electric power grid, at wind speeds of $4-20 \mathrm{~m} / \mathrm{s}$ and in an operating temperature range of $-20 \ldots+40^{\circ} \mathrm{C}$.

Failures on the system level that are relevant in this study are both a complete and a partial loss of energy conversion capability of the turbine.

\section{B. V90-2MW wind turbine}

Figure 3 shows the structure of the Vestas V90-2MW system. The first turbines of this type were installed in 2004. Like the V44, the V90-2MW is an upwind turbine with three blades and electrically driven yaw. Its rotor has a diameter of $90 \mathrm{~m}$, a weight of $38 \mathrm{t}$, and a nominal rotational speed of $14.9 \mathrm{rpm}$. The pitch control system with individual pitching capability for each blade continuously adapts the blade angle to the wind conditions in order to provide optimum power output and noise levels. In addition, it serves for speed control, turbine start-up and stop by aerodynamic braking. Similarly to the V44, a disc brake is located on the high-speed shaft.

In contrast to the V44 turbine, all V90-2MW systems apply hybrid gearboxes with one planetary and two parallel-shaft stages, from which the torque is transmitted to the generator through a composite coupling. A major difference from the V44 system is the generator concept: the V90-2MW contains a 4-pole doubly-fed asynchronous generator (DFIG) with wound rotor. A partially rated converter controls the current in the rotor circuit of the generator, which allows control of the reactive power and serves for smooth connection to the electric power grid.

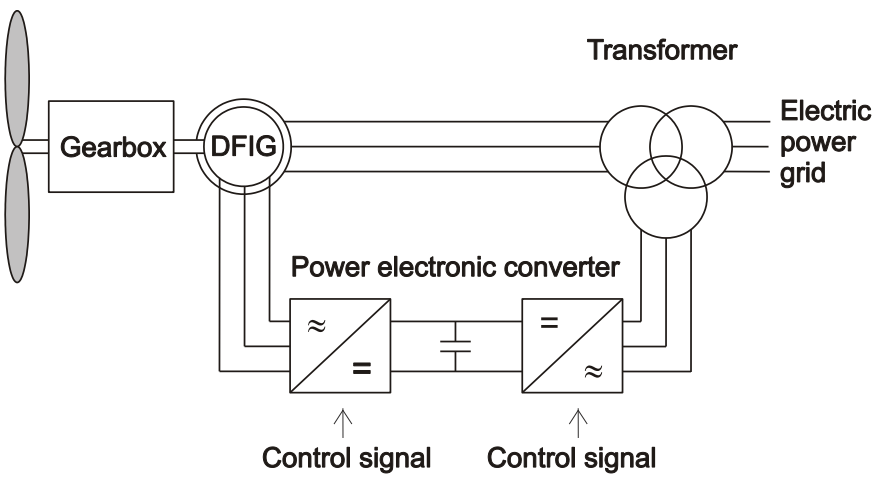

Fig. 3. Structure of the V90-2MW system with doubly-fed induction generator (DFIG) and partially-rated converter 
In particular, the applied DFIG concept (so-called OptiSpeed technology) allows the rotor speed to vary by $30 \%$ above and below synchronous speed. The electrical connection between the power converter and generator rotor requires slip rings and carbon brushes. The generator stator is, via a transformer, directly connected to the electric power grid. [2932]

The system function of the V90-2MW is to provide up to $2 \mathrm{MW}$ of electric power at $690 \mathrm{~V}$ and $50 \mathrm{~Hz}$ to the grid, at wind speeds of $4-25 \mathrm{~m} / \mathrm{s}$ and in a standard operating temperature range of $-20 \ldots+30^{\circ} \mathrm{C}$. Again in this case, system level failures of relevance in this study are the complete and the partial loss of energy conversion capability of the turbine.

\section{SUbSyStem SELECTION BASEd ON STATISTICAL ANALYSIS AND EXPERT JUDGMENT}

In order to focus the RCM study on the practically most relevant items, the selection of subsystems for detailed analysis has been based on both turbine-model specific failure statistics and expert judgement. The failure data used for statistical analysis covers the failures of $32 \mathrm{~V} 44-600 \mathrm{~kW}$ turbines located in Sweden from the period 1996-2005, which have been reported in the database [17]. This database includes failures that led to a wind-turbine downtime of at least $1 \mathrm{~h}$. Statistical data analysis for the V90-2MW system has been carried out based on data from [33]. It includes failures of 57 turbines located in Germany, from the period 2004-2008.

Both the frequency of failures in terms of the annual failure rate of a subsystem and the mean downtime resulting from a failure are relevant for the criticality assessment of an item. As it is the combination determining the impact on availability and thus on the production loss, it is advantageous to combine these two measures by multiplication. This results in the average downtime per wind turbine and year related to failures of a specific subsystem

$$
t_{\text {lost }}=\frac{\sum_{i=1}^{I} d_{i}}{\sum_{i=1}^{I} X_{i} \cdot T_{i}}
$$

with $d_{i}$ being the downtime due to failures of a subsystem in the time interval $i, X_{i}$ the number of wind turbines reporting to the database in time interval $i$, and $T_{i}$ being the duration of the time interval i.

Figure 4 shows the distribution of downtime over the subsystems of wind turbines of interest. Downtime due to external grid failures, inspections, service maintenance and other external causes has not been taken into account in this analysis. However, in case of the V90-2MW data, downtime due to retrofits and not failure-related component replacements is included in the data, which to some extent overestimates the relevance of rotor, control system and hydraulic system failures for the downtime. Note that due to the different failure-reporting schemes of the two data sources and the associated differences in subsystem categories, the results are not suitable for a comparison of the turbines; they do, however, serve the purpose of prioritization intended here.

In addition to failure statistics, expert opinion was taken into account in the identification of the most critical subsystems for in-depth analysis. The judgement of the RCM workgroup members having professional experience with wind turbine O\&M was assessed by means of questionnaires, from which a subsystem ranking was obtained. In case of both wind turbine models, highest priority was given to the gearbox, followed by the generator.

Based on the results of both the failure data analysis and the questionnaire assessment, the subsystems gearbox, generator, electrical system and hydraulic system were chosen for analysis in the RCM study. In spite of the significant average contribution of the control system to downtime, this system has not been included in the RCM analysis because its failures can hardly be influenced by means of preventive maintenance.

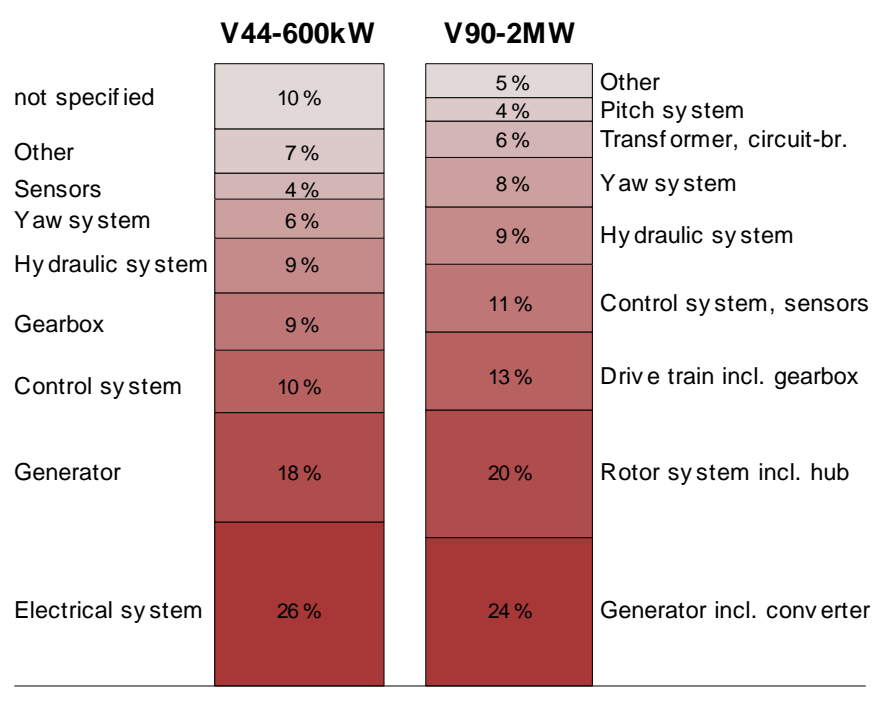

Fig. 4. Distribution of downtime $t_{\text {lost }}$ over subsystems in case of V44-600kW and V90-2MW systems operating onshore; data sources: [17, 33]

\section{RESUlTS AND DisCUSSION}

In the following, the RCM analysis results of the previously selected subsystems are presented. They are set in the context of related information from the open literature where this was possible. For each subsystem, the discussion is limited to the most dominant failure modes and causes. Due to the found broad similarity of failure modes, mechanisms and applicable countermeasures for the V44-600kW and the V90-2MW system, the results for the two turbines are presented together. Relevant differences in design, failure behavior or preventive measures will be pointed out in the context of the subsystemspecific results. Table 1 gives an overview over the order in which the results are presented.

\section{A. Gearbox}

The function of the gearbox in a wind turbine is the transmission of torque from the rotor to the generator shaft, providing the desired conversion ratio for speed and torque. The failure mode of interest is thus the loss of torque 
transmission capability. Gearbox failure can have severe consequences: In case of complete demolition, parts of the gearbox can constitute a risk for personnel. Oil spill of up to 1201 (V44) or 300-4001 (V90) of lubrication oil contained in the respective gearboxes can cause environmental impact. Gearbox failure is among the failures resulting in the longest average downtime and thus has a strong impact on production availability, and it can cause severe secondary damage, e.g. in the main bearing or the rotor shaft.

Table 1: Selection and structure of the presented RCM results

\begin{tabular}{l|l|c}
\hline Subsystem & Item & Section \\
\hline Gearbox & Bearings & V.A.1 \\
& Gearwheels & V.A.2 \\
& Lubrication system & V.A.3 \\
\hline Generator & Windings & V.B.1 \\
& Bearings & V.B.2 \\
& Slip rings and brushes (V90-2MW) & V.B.3 \\
\hline Electrical system & Rotor current control (V44-600kW) & V.C.1 \\
& Converter (V90-2MW) & V.C.2 \\
& Phase compensation unit (V44-600kW) & V.C.3 \\
\hline Hydraulic system & various & V.D \\
\hline
\end{tabular}

According to the experience and knowledge of the RCM workgroup, a failure cause considered valid for all gearbox components during different periods are design deficiencies, i.e. that components are under-dimensioned with respect to the real loads they are exposed to. This is not without controversy: While Musial et al. [34] state design deficiencies to be a major, mostly manufacturer-independent problem and cause of premature gearbox failure, poor maintenance and a lack of attention to monitoring this component are considered to significantly contribute to gearbox failure by others.

An additional failure cause of general validity for different gearbox components are manufacturing and installation deficiencies, which lead to increased friction or inappropriate high cyclic loading resulting in damage. Training of technicians for improving the quality of installation, service maintenance and repair as well as alignment check and monitoring of the wind-turbine drive train are thus considered important preventive measures against premature failure of gearboxes.

The bearings, the gearwheels and the lubrication system have been identified to be the components with highest relevance for gearbox failure and are thus discussed in more detail in the following. Failure of shafts in the gearbox is considered to occur as secondary damage only and has thus not been included in the RCM analysis.

\section{A.1 Gearbox bearings}

The majority of gearbox failures, according to the experience of the RCM workgroup often more than $60 \%$, originate from failure of gearbox bearings. This does not only apply to the V44 and V90 turbine models investigated here. The dominant role of bearing damage for gearbox failure is confirmed by the failure data in [17] to be valid for a variety of geared wind turbines.

The function of the gearbox bearings is to keep the shafts in their positions while allowing rotary motion at minimum friction. The failure mode of interest is the loss of this function, which is often induced by severe mechanical damage in form of flaking and cracks. Such bearing damages are in turn usually a result of progressed primary damage in form of wear, indentation, smearing, surface distress, corrosion or electric-current damage [35]. In parallel-shaft gearboxes of V44-600kW turbines as well as in the hybrid planetary-parallel gearboxes of the V90-2MW system, bearing problems have been observed mainly in the high-speed shaft (HSS) and the intermediate-speed shaft (IMS) bearings. In some cases, uptower repair of these bearings is possible. However, any failure in a planetary stage requires removal of the gearbox from the nacelle for external repair. The consequences of bearing failure range from partial (due to friction losses) or complete production losses (when severe bearing damage prohibits further operation) to comprehensive secondary damage of other components due to excessive vibration and strong heat generation. The latter implies even a risk of fire.

The main causes of bearing failure identified during the RCM analysis are overloading, inappropriate lubrication and corrosion. In all these cases, the failure characteristic is an increasing failure rate over time as damage accumulates, a reasoning supported by the quantitatively determined bearing failure characteristics of a $2 \mathrm{MW}$ gearbox published in [20].

Overloading of bearings is often a consequence of the design or installation deficiencies discussed earlier. It can lead to material fatigue and plastic deformation in a bearing. The resulting increased friction and heat evolution causes additional deterioration.

Inappropriate lubrication covers the lack of grease e.g. due to too long lubrication intervals, but also the use of wrong types of lubricant. Both failure causes result in metal-to-metal contact, wear and high contact temperature, which leads to damage of the inner bearing surfaces. This failure mechanism can as well result from the presence of particles in the lubricant to which the bearings are significantly more sensitive than any other part of the gearbox. In addition, inappropriate lubrication also includes over-greasing: an excess of grease between the rolling elements and the races causes the elements to slide instead of rolling, which can result in overheating of the bearing.

Suitable preventive measures to prevent these failure causes are the measurement of the oil pressure (being standard in V90-2MW) and temperature, as well as oil analysis. At present, oil samples are usually taken once a year and analyzed with respect to the content of additives, particles, and moisture as well as signs of corrosion. Online particle counters, which are available as a complement to existing CMS, are an option to monitor the oil quality continuously and enable earlier countermeasures in case of observed irregularities.

Another important cause of gearbox bearing failure is the presence of water or moisture in the gearbox oil, a factor that is usually strongly dependent on the location of the wind 
turbine. Moisture can on the one hand lead to corrosion through oxidation of the metallic components. In addition, hydrogen ingression into the steel reducing the material strength has been put forward as a possible explanation for surface failures [36]. However, there are alternative theories, which include interaction with the additives present in the grease, tribo-chemical effects having influence on the localized crack behavior [37]. As mentioned above, oil analysis is a suitable measure to identify moisture in the gearbox oil. An alternative is online moisture-detection with an automatic system, but this is not considered to be economic on machines in the $\mathrm{kW}$ range. A both cheap and effective option to prevent the ingress of moisture into the gearbox is the installation of a filter dryer in the top casing that dehumidifies the air flowing into the gearbox during thermal cycles.

Vibration-based condition-monitoring systems (vibrationCMS) and complementary measurement of bearing temperatures detect approximately $90 \%$ of all impending bearing failures, according to the experience of the RCM workgroup. In this way, secondary damage resulting from excessive vibration and heat generation can be prevented effectively in many cases, however, usually not the bearing damage itself. A major difference between vibration and temperature monitoring is that vibration-CMS typically provide a pre-warning time (P-F interval) in the range of several weeks to months while this is only in the range of hours to days in case of temperature-based detection (see also Fig. 5). The application of vibration-CMS is considered to be state of the art on MW turbines. However, vibration monitoring and vibration-based diagnosis of planetary gearbox stages is still challenging at present and an improvement of condition-monitoring technology for this purpose is subject to intensive development activities today.

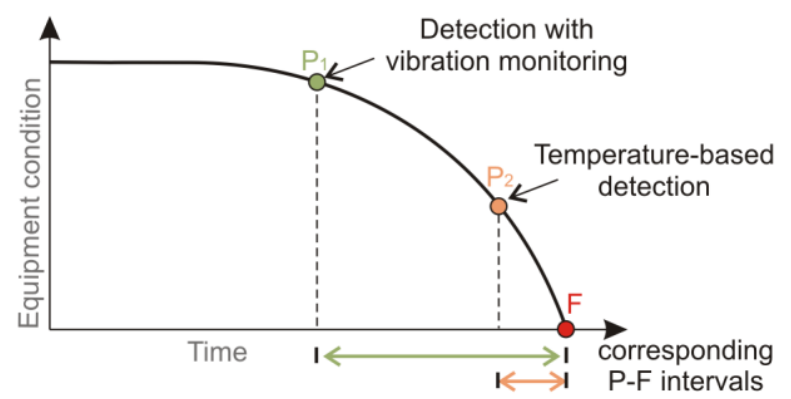

Fig. 5. Intervals between detection of a potential failure $\mathrm{P}$ and functional failure F (P-F intervals) for vibration-based vs. temperature-based monitoring

A visual-inspection technique increasingly applied to wind turbines to assess the condition of gearbox bearings as well as gearwheels is borescope inspection (also known as endoscopy). Combined with digital imaging technology, this enables even remote condition-assessment by gearbox experts. Borescope inspection is not only applied in case impending failure is detected by vibration or temperature measurements, but also without any indication of irregularities. The V90-2MW as well as the majority of other contemporary wind turbines provide an opening in the gearbox casing, which allows easy access for borescope inspection. Due to the compact design of gearboxes, not all components can be inspected with this technique, e.g. the HSS bearings of V90$2 \mathrm{MW}$ are not accessible for borescope inspection.

The cost-effectiveness of measures for prevention and early detection of bearing damages is considered high as it serves to prevent severe secondary damage to the gearbox. In this way, the lifetime of the gearbox can be extended. Up-tower repair may be possible instead of significantly more expensive removal and external repair of the gearbox. In case of a necessary replacement, a higher residual value of the gearbox can be preserved.

\section{A.2 Gearwheels}

The function of the gearwheels is to transmit mechanical power while converting speed and torque at the desired ratio. The failure modes considered most relevant by the RCM workgroup are pitting, scuffing, and tooth breakage.

Pitting describes the failure of a material due to surface fatigue, being a result of continuous surface stress. It is characterized by removal of material and the formation of cavities and cracks, which can progressively increase in size and destroy the tooth shape, resulting in significantly increased friction or even tooth breakage [38]. Micro-pitting (or grey staining) as the onset of pitting is very common on gearwheels and is a normal sign of usage. More severe pitting can have different causes: in addition to (i) overloading and (ii) metal particles in the lubricant leading to high local stress levels, also (iii) false brinelling on the teeth evolving during standstill of the wind turbine leads to pitting. The failure characteristic of this failure mode is an increasing failure rate over time. Suitable preventive measures tackle the failure causes above: In order to avoid excessive load on the gearbox, it is desirable to avoid the utilization of the mechanical brake located on the high-speed shaft. For the same reason, it is recommended to ensure the correct alignment of the drivetrain components. Lubricant-contamination related issues are addressed by means of regular oil analysis or online particle-counting. In addition to oil analysis, it is common practice today to indicate the presence of metal particles by means of a magnetic plug in the gearbox. Inline magnetic filtering as an alternative preventive measure does not only indicate, but also remove metal particles. Finally, long periods of standstill are to be avoided to prevent false brinelling on gear teeth.

Scuffing describes damage on the tooth surface in the form of scratch lines resulting from welding and tearing of the tooth surface by the flank of the mating tooth. This is caused by an insufficient (or wrong type of) lubricant film leading to metalto-metal contact of the interacting gear teeth. Even under appropriate lubrication conditions, scuffing occurs when the load exceeds the scuffing load capacity of the oil, a quantity which is usually determined in a standard lubricant test and which is dependent on the extreme-pressure additives in the oil (cf. [39]). Scuffing leads to higher friction and heat generation and the release of metal particles into the oil, which are a potential source of secondary damage as discussed above. In 
contrast to the further failure modes of gearwheels discussed here, the failure characteristic of scuffing is considered to be random failure, i.e. a constant failure rate over time. Resulting from the failure causes given above, the choice of appropriate lubricant type and regular quality control through oil analysis together with minimizing overload conditions are possible preventive measures.

Tooth breakage in wind turbine gearboxes can occur as a secondary damage of pitting or scuffing when the excessive removal of material has decreased the strength of a gear tooth. Further causes of tooth breakage are overload due to misalignment or design deficiencies, and fatigue, which can in particular result from frequent emergency stops. The mechanical emergency braking sequence introduces excessive oscillating mechanical loads which can reach up to $>250 \%$ of the rated torque [40]. Tooth breakage results in high friction, strong heat evolution, and potentially secondary damage caused by the metal particles. The preventive measures discussed above are thus also effective against tooth breakage. In addition, vibration-based CMS can assist in revealing misalignment and is an effective measure for early detection of gear damage. Finally, a functioning lubrication system is of crucial importance for the lifetime of both gearbox bearings and gearwheels. It is thus discussed in a separate section in the following.

\section{A.3 Gearbox lubrication system}

The function of the gearbox lubrication system is to supply lubricant to the contact areas of interacting gearwheels and to the bearings, at right temperature and viscosity, to filter the lubricant and to provide cooling for the gearbox. The lubrication systems of V44-600kW and V90-2MW differ in design: While the lubrication system of the V44 consists of a single inline circuit driven by a mechanical pump, the corresponding system of the V90-2MW consists of three separate circuits: (a) an inline cooling and lubrication circuit with a mechanical pump, (b) an additional cooling circuit with an electric pump, which starts operation when the oil temperature reaches a threshold value, and (c) an offline filter circuit. As indicated in Fig. 6, oil filtration occurs by means of a coarse $(25 \mu \mathrm{m})$ inline filter in the main lubrication oil circuit as well as with the finer offline filter $(3 \mu \mathrm{m})$. In addition to particles, the offline filter even removes moisture contained in the oil. In case of a particle counter being installed, this is located in the offline circuit. In contrast to the V44-600kW, an analogue oil-pressure measurement in the inline circuit is standard on the V90-2MW. The lubrication systems of both turbines include systems for heating the gearbox oil.

According to the RCM group, the dominant failure in the lubrication system is high oil temperature, which results in an insufficiently thin oil film. In the large majority of cases, this is caused by a failure of the temperature control system, more seldom by a defect in the cooling circuit. No preventive measures to counteract this type of failure have been identified. However, a modification of the control system was proposed to reduce the impact on production loss: by introducing lower alarm levels for the oil temperature, a warning alarm could be issued in good time before the wind turbine is stopped automatically due to a critical level of the oil temperature; in that case, the operation of the wind turbine could be continued at reduced power until the maintenance personnel arrives at the turbine.

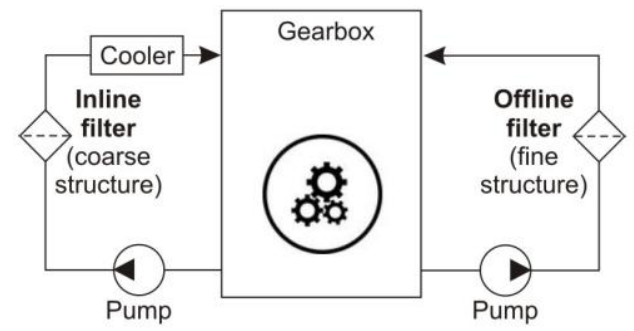

Fig. 6. Gearbox lubrication system of the V90-2MW with inline and offline filtration of oil

A second important failure of the lubrication system is a too low temperature of the oil, which in that case has a too high viscosity to ensure appropriate lubrication. This can be caused by failure of the gearbox-oil heating system, but can even occur in case of a functioning heating system due to nonhomogeneous heating and insufficient mixing of the oil. A proposed measure to prevent secondary damage resulting from low oil temperature is measuring the temperatures at relevant positions and not permitting start-up of the turbine while one of these is below a threshold value.

In case of the V44, a third relevant failure of the lubrication system is insufficient oil filtration, with the potential consequences for the gearbox bearings and gears discussed above. Blockage of the filter in the main oil circuit causes a bypass to open unless the filter has been replaced. The oil is circulated without filtration in this case. According to the present practice, the inline oil filter is replaced every 12 months, an interval considered appropriate by the RCM workgroup. Insufficient filtration can be prevented by means of offline filtration. In the V90-2MW, the offline filter continuously removes particle and moisture contamination from the oil, which makes a blockage of the inline filter very unlikely. Suitable measures to detect insufficient filtration are the installation of an online particle-counter or measurement of differential pressure over the inline filter, which could indicate and provide an alert when the filter is blocked. An interesting observation is that the filter surface is often only partially utilized because air is enclosed in the upper part of the filter. The introduction of an air-bleed point in the filter enclosure could enable a better utilization of the available filter surface and provide a longer useful life of the filter.

A fourth but less frequent failure of the lubrication system is leakage or loss of oil leading to low oil pressure. Leakage can occur at a slow rate e.g. at the shaft seals or at badly installed filters while sudden loss of oil from the lubrication system can e.g. be caused by a rupture of an oil hose. The only preventive measures in this context would be an improved training of maintenance technicians to ensure the correct 
installation of oil filters or the development of filter designs for foolproof mounting. In order to detect oil leakage or loss, gearboxes are presently checked visually during service. Measurement of the oil pressure as implemented in the V902MW facilitates detecting loss of oil at an early stage.

\section{B. Generator}

The function of the generator is to convert the mechanical power from the high-speed shaft to electrical power fed into the electric power grid. Generator failure is in the large majority of cases caused by winding or bearing failure. This does not only apply for the wind turbines analyzed here, but for a wide variety of wind-turbine generators, as shown by Alewine and Chen [22]. According to these authors, rotor failures dominate in smaller machines having mostly a random wound rotor design, while modern generators with formwound coils are more robust. In machines $\geq 1 \mathrm{MW}$, bearing failures constitute more than half of all generator failures.

\section{B.1 Generator windings}

The category of generator windings incorporates both the windings of the stator as well as the wound rotor. The functions of the windings are to lead electric currents while preventing undesired short-circuits. The consequences of winding failure range from a limited electric unbalance in the output power to emergency braking followed by standstill of the wind turbine. In addition to the required re-winding of the generator, the consequences can also include secondary damage of the rotor-current control unit (V44) and of the gearbox, the latter resulting from the excessive loading during emergency stops (see Section A.2).

Failures of the generator windings can be a short-circuit due to a failed insulation, or the loss of conduction, i.e. the occurrence of an open circuit. Short-circuit failure occurs due to melting of the insulation due to overheating, due to material degradation (aging) of the insulation or due to mechanical impact, predominantly caused by vibrations (e.g. due to bearing damage). According to [22], a common root cause is thermal cycling damage emerging during cycling between cold ambient temperature and operating temperature due to different thermal expansion behaviour of conductor and insulating material. Insulation failure is facilitated in presence of moisture. The frequency of short-circuit failure increases with time. Measures to prevent failures of the insulation are: (1) temperature measurements in the windings, usually being part of the System Control and Data Acquisition (SCADA) system in contemporary turbines, and (2) the early detection of bearing failures by means of vibration-monitoring with a CMS.

Open-circuit failure of the generator windings is caused by broken windings or failing contacts at connections. The underlying failure cause can be fatigue as a consequence of excessive vibrations or thermal cycling, or material defects in the copper conductors. To avoid operation at high vibration levels is thus also a preventive measure against open-circuit failures. Thermography can be applied to detect initiating damage in the conductor or in contacts since a reduced cross section usually causes local hot spots. An additional method to identify impending failure of this type is the application of a so-called motor tester during standstill of the generator, which enables diagnosis based on an injected test signal. Among the analyzed wind turbines, only the rotor windings in the V90$2 \mathrm{MW}$ generator are accessible for diagnostic measurements. With respect to the failure characteristic, the probability of open-circuit failure of the generator windings is either constant or increasing over time, depending on the underlying failure mechanism.

\section{B.2 Generator bearings}

The function of the generator bearings is to keep the generator rotor shaft in its position with a minimum amount of friction for rotary motion. The occurrence of high friction due to cracks or flaking is considered to be the main failure mode. Failed generator bearings can usually be replaced on site.

Bearing damage in the generator can be caused by misalignment or inappropriate lubrication through the mechanisms already discussed in the context of gearbox bearings. Another common cause is electric current flowing through the generator bearings, leading to electrical erosion. Both the mechanically and the electrically initiated causes have as well been reported by [22] to be common failure causes in wind-turbine generators in general. Bearing damage is, according to the experience of the RCM workgroup, accelerated by insufficient maintenance and accumulates over time. The corresponding failure characteristic is thus an increasing failure rate. Preventive measures include a strict compliance with the lubrication scheme, which prescribes lubrication of the generator bearings every six months as a part of the regular service, or the installation of an automatic lubrication system. According to [41], extending the preventive maintenance of generator bearings including a change of lubricant effectively reduced the frequency of generator bearing failures in Vestas turbines in the past. Vibration-CMS facilitate an early detection of misalignment, as stated in [22].

The causes of bearing currents in wind turbines are not fully understood today and are subject of ongoing investigations. Among the suspected causes are winding damage in the generator rotor, ground currents and unbalanced electrical characteristics in the power electronics connected to the generator electrical circuits. The current flow through the bearings involves the formation of sparks, which at the contact surfaces have a similar effect as electric-arc welding; locally, the material is tempered, re-hardened or melted, in the latter resulting in the formation of small craters [35]. Again, the failure characteristic is increasing with time due to the accumulating nature of the damage, but also with the current amplitude. Vibration-based CMS and temperature measurements, the latter being standard in the V90-2MW model, can be applied for early bearing-damage detection and prevention of secondary damage as discussed earlier. This is recommendable as, according to [22], even non-catastrophic bearing failure can create sufficient heat to severely damage, 
e.g. the rotor winding or the shaft. In order to assess if bearing current is present in a generator, it is possible to measure the high-frequency electromagnetic emissions originating from the sparks. In case of detected bearing current, the application of hybrid bearings can be taken into consideration, in which the rolling elements are made from an insulating ceramic material. Generators in the V90-2MW are usually by default equipped with bearings of this type [32].

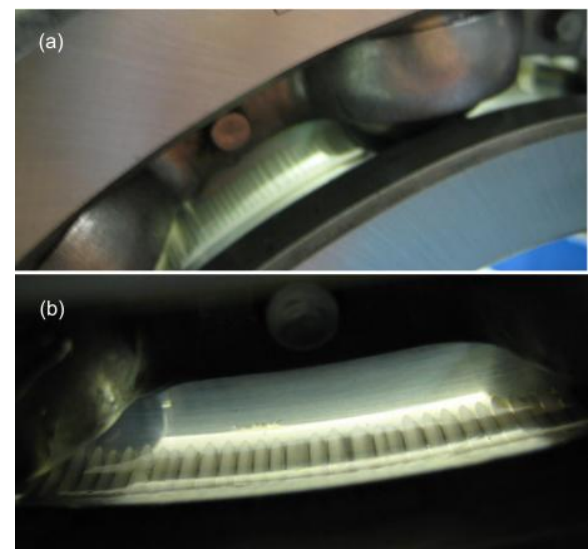

Fig. 7: Typical bearing-current induced damage in the form of fluting on the inner (a) and outer (b) raceway of a wind-turbine generator bearing

\section{B.3 Generator slip rings and brushes (V90 only)}

Generator components being both maintenance- and failure intensive are the slip rings and carbon brushes providing the electrical contact to the V90-2MW generator rotor. Carbon dust originating from the wear of the brushes favours electric spark-over, which damages the slip ring. This issue has been solved successfully by means of a suction system for continuous removal of the carbon dust during operation. In addition, the quality of the brushes has improved significantly, which significantly extended slip-ring life to approximately 2 years today. According to [22], carbon brush life is usually affected by the environmental conditions temperature and humidity. Slip rings and carbon brushes are inspected every 6 months during service and are replaced depending on their condition. Continuous condition-monitoring of the brushes, having the benefit of preventing damage from over-worn brushes, can be implemented using electrical contacts in the brushes or visual monitoring of the brush thickness by means of a camera.

\section{Electrical system}

\section{C.1 Rotor Current Control (V44-600kW)}

The most frequently failing item in the electrical system of the V44-600kW is the RCC unit explained in Section III.A. This is clearly indicated by the turbine-specific failure statistics and in agreement with both the experience of the RCM workgroup and [41]. In average, the RCC unit has to be replaced at least once during the wind-turbine lifetime. In spite of its attachment to the generator, the RCC is discussed as a part of the electrical subsystem here in accordance with the categorization of failure data of the V44 (see Fig. 4). Please note that the discussion below refers to the RCC of generators manufactured by Weier, out of two generator models being the one found predominantly in V42 and early V44 turbines.

The function of the RCC unit is a fast control of the generated electric power by regulating the rotor current, as explained in Section III.A. Failure of the RCC unit results in a loss of this current control capability. However, the impact on the system function, i.e. if a full or a partial loss of the energy conversion capability is caused, depends on the failed part of the RCC. Due to the fact that failure of the power electronics unit clearly dominates over failures of the RCC microprocessor unit and the resistor unit, only failure modes and causes of the first are discussed in the following. Failure of this unit usually permits continued operation of the wind turbines at reduced power of max. $300 \mathrm{~kW}$. In that case, the generator operates with a fixed rotor resistance (see also Fig. 2 ). In some cases, failure of the power-electronic unit of the RCC is caused by loose contacts or cable twist and thus by mechanical impact, e.g. due to vibrations. However more frequent is the occurrence of IGBT failure. According to the RCM workgroup, this has been observed predominantly in the mornings and evenings, i.e. during times with large changes in power demand and generation and therefore frequent coupling activities in the power grid. This observation suggests that the failure is related to grid disturbances like voltage dips or frequency variations. The frequency of failure of the RCC power-electronics unit tends to increases with component age. Overheating-related failure of this unit occurs also as a secondary failure due to high temperature in the nacelle, i.e. after a defect in the cooling system of the gearbox.

The different failure causes explained require different measures for prevention: Vibration-related failure can be influenced through the level of vibration, e.g. by applying continuous vibration-monitoring and preventive bearing replacement before strong vibrations occur. Age-based preventive replacement is a theoretically possible, but not an economic measure.

\section{C.2 Converter (V90-2MW)}

In a variable-speed wind turbine with DFIG like the V90$2 \mathrm{MW}$, the function of the converter is to feed the generator rotor circuit with an electric current of desired amplitude and frequency in order to ensure the desired output of active and reactive power from the stator to the grid. Depending on the operating speed, the converter either transmits electric power from the generator rotor circuit to the grid (super-synchronous operation) or vice versa (sub-synchronous operation), see e.g. [42]. As shown in Fig. 3, the converter system consists of a rotor-side and a grid-side converter in back-to-back configuration. The rotor-side converter controls the current to the rotor whereas the grid-side converter controls the DC link voltage [43]. In addition to these two power-electronic units with IGBT switches, the converter subsystem includes corresponding microprocessor (or control) units. The converter is water-cooled by means of a pump-driven cooling 
circuit. High failure rates of the converter systems found in V80 and early V90-2MW turbines have decreased. However, the converter system is still a source of failure in later turbines of the V90-2MW series. Salty environments, grid disturbances, insufficient cooling and condensation problems negatively impact the failure frequency of the converter system according to the RCM workgroup. The consequences of converter failure are mainly limited to production loss. In case of failure, the turbine is stopped smoothly by means of the aerodynamic brake so that excessive loading of the drive train components and potential secondary damage of this is avoided.

The failure modes of the converter identified in the present study are (a) open-circuit failure, i.e. an interruption of the electrical connection, and (b) a malfunction of the rotor current and frequency control. A common cause is the failure of the microprocessor units, a problem that can be addressed e.g. with software updates or by using dust- and moisture-protected circuit-boards, but usually not with preventive maintenance. Another cause is failure of the power-electronic components with potential causes ranging from high ambient temperature, vibration, moisture or condensation problems and component aging to disturbances from the grid. Based on that, possible preventive measures are those reducing or monitoring the given failure causes, such as reduction of vibration in the power-electronics unit by design modifications, or monitoring of vibration and bearing temperatures. Potential design modifications of converters for wind turbines aiming at increased fault tolerance are discussed in [44].

\section{C.3 Phase compensation unit (V44-600kW only)}

Besides the RCC unit discussed above, a second frequently failing component of the V44 electrical system is the capacitor bundle at the bottom of the tower providing reactive power to the generator. Failure of capacitors is a common cause of fire in wind turbines. A lack in manufacturing quality is considered to be the main cause of failure. According to the current maintenance practices, the capacitors are visually inspected during the regular service.

\section{Hydraulic system}

The function of the hydraulic system in the considered wind turbines is (a) to operate the rotor-blade pitch mechanisms for controlling the angle-of-attack of the wind, which includes aerodynamic braking capability, and (b) to actuate the mechanical disc brake. The hydraulic system comprises two different pressure levels, but only a single hydraulic pump: the pitch system is operated at a level of 200bar, while the mechanical brake, connected with a pressure reducing valve, is actuated at a level of $30 \mathrm{bar}$.

The theoretical worst-case scenario of a full loss of braking capability resulting in over-speeding of the turbine, which is afflicted with considerable risk for persons and installations near the wind turbine, is considered highly improbable as this is prevented by two different safety systems for the pitch system and the mechanical brake: In case of emergency, a safety valve releases the pressure from the hydraulic pitch actuators and in this way allows the blades to be pitched out of the wind solely by the aerodynamic forces; emergency operation of the mechanical brake is ensured by a hydraulic accumulator with stored pressure.

The two failure modes selected by the RCM workgroup for analysis are (1) a loss of pitching functionality or a too slow pitch as well as (2) an unintentional activation of the mechanical brake. The consequences of these include a partial or full loss of power generation capability, but no risk for personnel or the environment. Secondary damage to the drive train can result from pitch errors of single blades, which lead to unbalances and thus impose high cyclic load on the drive train components.

The most common cause of too slow pitching or loss of pitching functionality is a failure of a control valve due to wear-out. The failure characteristic is thus a failure rate increasing with the age of this component. At present, hydraulic valves are maintained with a run-to-failure strategy. A possible preventive measure is a scheduled replacement of the valves at the age of around 10 years. However, a central cause for the wear-out of the hydraulic control valves is moisture and particle contamination of the hydraulic oil. A more effective damage-preventing measure in this context is thus an additional offline filtration of the hydraulic oil or a measurement of the moisture content for early detection. According to the present common practice, the hydraulic oil of the V44-600kW is exchanged every 4-5 years, while an oil change in the V90-2MW hydraulic system is usually required after 3 years. It is expected that the implementation of offline filtration significantly extends the oil-change intervals for the hydraulic oil.

Another common cause of pitch failure is too low pressure in the hydraulic system. This can result from failure of a hydraulic pump, failure of a control valve or the $24 \mathrm{~V}$ transformer feeding it, or failure of an accumulator. Accumulators store energy by means of pressurized gas contained in a rubber bladder. As the rubber ages, the probability of cracks or rupture leading to a pressure loss in the accumulator increases. Low pressure in the hydraulic system can also be a result of oil leakage, e.g. due to a rupture of an oil hose.

The other failure mode of interest, the unwanted activation of the mechanical brake, is disadvantageous as it imposes large loads on the wind-turbine drive train. It is mostly caused by an error in the control system and can thus hardly be influenced by maintenance. However, in some case it is caused by oil leakage through an upstream valve which causes a pressure build-up at the disc brake, a problem that could be overcome by means of a drainage system [45].

In addition to the scheduled exchange of hydraulic oil explained above, the present maintenance practices for the hydraulic system cover a visual check of its components to detect oil leakage, the exchange of filters as well as functional tests of the control valves and the hydraulic pump during the regular service every 6 months. 


\section{CONCLUSIONS}

A Reliability-Centred Maintenance analysis of the two wind turbine models V44-600kW and V90-2MW has been carried out. The study has been performed in a workgroup involving a wind turbine owner and operator, a maintenance service provider, a provider of condition-monitoring services and wind turbine component supplier as well as researchers at academia. The analysis forms the basis for the development of quantitative models for maintenance strategy selection and optimization. Its scope is limited to those subsystems and failure modes being the main drivers of wind-turbine unavailability, namely the gearbox, the generator, the electrical system and the hydraulic system. For these subsystems selected for in-depth analysis based on failure statistics and expert opinion, it has identified the most relevant functional failures, their causes and suitable preventive measures.

Regarding the failure modes, causes and underlying mechanisms, wide-ranging parallels between the considered wind-turbine models are recognized. Compared to the V44-600kW design, comprehensive additional failurepreventive measures have been found implemented in the V90$2 \mathrm{MW}$ series. In numerous cases, the identified issues were found to be valid also for a wide variety of other wind turbines, as a comparison with the cited references reveals.

Among the failure causes identified in this study, vibration has been found to play a central role as a cause for mechanical failure of a variety of wind turbine components. Measures aiming at prevention or early detection of bearing damage are therefore concluded to be particularly effective. A second conclusion from this concerning maintenance modeling is that quantitative maintenance-optimization models that are based on the common assumption of independent failure of components run the risk of systematically underestimating the benefit of vibration-monitoring.

Both the frequency and the quality of service maintenance have been found to significantly impact the technical condition and failure rate of wind turbines. This underlines the important role of maintenance besides the inherent, design- and qualitydependent reliability of a wind turbine for its operating availability. A perceived challenge in this context, the lack of experienced technicians resulting from the rapid increase in wind power installations, should be tackled by enhanced training of maintenance personnel. Another step considered important by the RCM workgroup is to overcome the present common practice to aim maintenance decisions at short-time cost savings instead of a long-term minimization of life-cycle cost. This can be achieved by developing and introducing databased decision-support tools in maintenance management. The mathematical models for maintenance strategy selection and optimization that are being developed based on the presented RCM study aim at contributing to this process. However, the amount and depth of wind-turbine failure and maintenance data available today is insufficient for the application of sophisticated quantitative methods in practice. The standardized and automated collection of in-depth failure and maintenance data is thus concluded to be an important step in order to enhance the reliability, availability and profitability of wind turbines.

\section{ACKNOWLEDGMENT}

The authors gratefully acknowledge the comprehensive contributions of the members of the RCM workgroup in this study, I. Aasheim (SKF Renewable Energy), U. Halldén (Triventus), B. Mathiasson (SKF Sweden), P. Schmidt (SKF Denmark) and T. Svensson (Göteborg Energi). Failure data of the V90-2MW system was used for statistical analysis with kind permission of Vattenfall. Pictures of bearing-current related damage in wind-turbine generator bearings were provided by Triventus.

\section{REFERENCES}

[1] EWEA, "Wind in power - 2010 European statistics," 2011.

[2] EWEA, "Annual Report 2009 - A Breath of Fresh Air," 2010.

[3] E. Hau, Wind Turbines: Fundamentals, Technologies, Application, Economics 2nd ed. Berlin Heidelberg: Springer, 2006.

[4] T. S. Obdam, L. W. M. M. Rademakers, and H. Braam, "Flight Leader Concept for Wind Farm Load Counting: Offshore Evaluation," Wind Engineering, vol. 34, pp. 109-122, 2010.

[5] D. McMillan and G. W. Ault, "Quantification of Condition Monitoring Benefit for Offshore Wind Turbines," Wind Engineering, vol. 31, pp. 267-285, 2007.

[6] S. Faulstich, B. Hahn, and P. J. Tavner, "Wind turbine downtime and its importance for offshore deployment," Wind Energy, vol. 14, pp. 327-337, 2011.

[7] J. A. Andrawus, J. Watson, M. Kishk, and H. Gordon, "Optimisation of Wind Turbine Inspection Intervals," Wind Engineering, vol. 32, pp. 477-490, 2008.

[8] J. Nilsson and L. Bertling, "Maintenance Management of Wind Power Systems Using Condition Monitoring Systems-Life Cycle Cost Analysis for Two Case Studies," IEEE Transactions on Energy Conversion, vol. 22, pp. 223-229, 2007.

[9] F. Besnard and L. Bertling, "An Approach for Condition-Based Maintenance Optimization Applied to Wind Turbine Blades," IEEE Transaction on Sustainable Energy, vol. 1, pp. 77-83, 2010.

[10] F. Besnard, M. Patriksson, A.-B. Strömberg, A. Wojciechowski, K. Fischer, and L. Bertling, "A Stochastic Model for Opportunistic Service Maintenance Planning of Offshore Wind Farms," in IEEE PES PowerTech 2011, Trondheim, Norway, 2011.

[11] J. Moubray, Reliability-Centered Maintenance. New York: Industrial Press Inc., 1997.

[12] M. Rausand and A. Høyland, System Reliability Theory: Models,Statistical Methods, and Applications, 2nd ed. Hoboken, New Jersey, USA: John Wiley \& Sons Inc., 2004.

[13] R. Dekker, "Application of maintenance optimization models: a review and analysis," Journal of Reliability Engineering and System Safety, vol. 51, pp. 229-240, 1996.

[14] A. K. S. Jardine and A. H. C. Tsang, Maintenance, Replacement, and Reliability - Theory and Applications. Boca Raton, USA: Taylor \& Francis Group, 2006.

[15] L. Bertling, R. Allan, and R. Eriksson, "A reliability-centered asset maintenance method for assessing the impact of maintenance in power distribution systems," IEEE Transactions on Power Systems, vol. 20, pp. 75-82, Feb 2005.

[16] S. Faulstich, B. Hahn, and P. J. Tavner, "Wind turbine downtime and its importance for offshore deployment," Wind Energy, vol. 14, pp. 327-337, 2010.

[17] "Felanalys - Database of failures for Swedish wind turbines 1989 2005," ed: Data compiled by SwedPower AB, Stockholm, on behalf of STEM and ELFORSK, 2005. 
[18] P. J. Quinlan, "Reliability centered maintenance applied to wind park operations," in Sixth ASME Wind Energy Symposium, Dallas, USA, 1987.

[19] J. Andrawus, "Maintenance optimization for wind turbines," $\mathrm{PhD}$ thesis, Robert Gordon University, Aberdeen, United Kingdom, 2008.

[20] R. Bellens and P. Chemweno, "Business case for condition based maintenance of wind turbine gearboxes," Master's thesis, Katholieke Universiteit Leuven, Leuven, 2010.

[21] S. Faulstich, B. Hahn, H. Jung, and K. Rafik, "Suitable failure statistics as a key for improving availability," in European Wind Energy Conference (EWEC), Marseille, France, 2009.

[22] K. Alewine and W. Chen, "Wind turbine generator failure modes analysis and occurrence," presented at the Windpower 2010, Dallas, Texas, USA, 2010.

[23] H. Arabian-Hoseynabadi, H. Oraee, and P. J. Tavner, "Failure Modes and Effects Analysis (FMEA) for wind turbines," International Journal of Electrical Power \& Energy Systems, vol. 32, pp. 817-824, Sep 2010.

[24] P. J. Tavner, A. Higgins, H. Arabian, H. Long, and Y. Feng, "Using an FMEA method to compare prospective wind turbine design reliabilities," in European Wind Energy Conference (EWEC), Warsaw, 2010.

[25] L. Bertling, "RCM-studie Birka Nät och KTH - en studie av felorsaker baserad på statistik och praktik (RCM study Birka Nät and KTH - a study of failure causes based on statistics and practical experience)," KTH, Stockholm, 2001.

[26] K. Fischer, F. Besnard, and L. Bertling, "A Limited-Scope Reliability-Centred Maintenance Analysis of Wind Turbines," in European Wind Energy Conference EWEA, Brussels, 2011, pp. 89-93.

[27] J. Ribrant and L. Bertling, "Survey of failures in wind power systems with focus on Swedish wind power plants during 1997. 2005," IEEE Transaction on Energy Conversion, vol. 22, pp. 167173, 2007.

[28] M. Lindqvist and J. Lundin, "Spare Part Logistics and Optimization for Wind Turbines - Methods for Cost-Effective Supply and Storage," Master's thesis, Uppsala University, Uppsala, 2010.

[29] "V90-1.8MW \& 2MW - Built on experience," ed. Randers, Denmark: Vestas Wind Systems A/S, 2007.

[30] "Guideline Reference Designation System for Power Plants, RDSPP - Application Explanations for Wind Power Plants," VGB 116 D2, 2007.

[31] "V90-1.8MW/2MW," ed. Randers, Denmark: Vestas Wind Systems A/S, 2009.

[32] "V90-1.8MW/2MW," ed. Randers, Denmark: Vestas Wind Systems A/S, 2010.

[33] R. Balschuweit, "Beanspruchungs- und Schadensanalyse von Windenergieanlagen am Beispiel der Vestas V90-2MW," Master's thesis, TFH Berlin in cooperation with Vattenfall, Berlin, 2009.

[34] W. Musial, F. Butterfield, and B. McNiff, "Improving Wind Turbine Gearbox Reliability," in European Wind Energy Conference Milan, Italy, 2007.

[35] SKF, "Bearing failures and their causes - Product information 401," SKF, 1994.

[36] P. Ruo and A. V. Olver, "Hydrogen in lubricated contact," in $2^{\text {nd }}$ PhD Conference on Artificial Intelligence for Industrial Applications, Hannover, Germany, 2008.

[37] R. Pasaribu, SKF Engineering and Research Centre, Netherlands ed, 2011.

[38] M. Lucente, "Condition Monitoring System in Wind Turbine Gearbox," Master's thesis, KTH in cooperation with NTNU, Stockholm, 2008.

[39] D. J. Hargreaves and A. Planitz, "Assessing the energy efficiency of gear oils via the FZG test machine," Tribology International, vol. 42, pp. 918-925, 2009.

[40] E. Kornbek, "Soft braking system for wind turbines," in European Wind Energy Conference Nice, France, 1999, pp. 861-862.

[41] O. Carlson, M. Helmer, and C. Liljegren, "Analys av havererade asynkrongeneratorer (Analysis of failed asynchronous generators)," Chalmers University of Technology, Gothenburg, Sweden, 2001.

[42] J. F. Manwell, J. G. McGowan, and A. L. Rogers, Wind Energy Explained: Theory, Design and Application, 2nd ed. Chichester: John Wiley and Sons Ltd, 2009.

[43] K. Nilsson, "Torque estimation of double fed induction generator using a dynamic model and measured data," Master's thesis, Lund University, Lund, 2010.

[44] H. Polinder, H. Lendenmann, R. Chin, and W. M. Arshad, "Fault Tolerant Generator Systems for Increasing Availability of Wind Turbines," in European Wind Energy Conference and Exhibition, Marseille, France, 2009.

[45] C. Roed, O. M. Jeppesen, K. L. Jensen, and C. Ahler, "Hydraulic system and method for operating a brake of a wind turbine," 2011.

\section{BIOGRAPHIES}

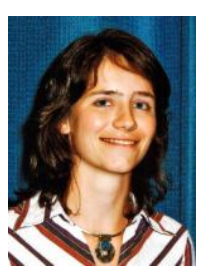

Katharina Fischer (M'10) was born in Germany in 1979. She received the Diplom degree in electrical engineering in 2002 from Leibniz Universitaet Hannover, Germany, and finalized her Ph.D. degree in the field of thermo-mechanical failure of high-temperature fuel cells in the mechanical engineering faculty of the same university in 2008. Since 2009 , Dr. Fischer is a postdoctoral research fellow at the Division of Electric Power Engineering, Department of Energy and Environment, at Chalmers University of Technology in Gothenburg, Sweden, and part of the Wind Power Asset Management (WindAM) group. Her current research interests include reliability analysis and maintenance optimization for wind power plants.

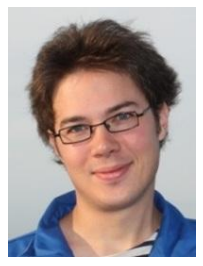

François Besnard ( $\left.\mathrm{S}^{\prime} 07\right)$ was born in Rennes, France, in 1983. He received the M.Sc. degree in electrical engineering from the Royal Institute of Technology (KTH), Stockholm, Sweden and from The Ecole Supérieure d'Electricité (SUPELEC) both in 2007 and the Tech. Licentiate degree in electrical engineering from KTH in 2009. He is currently a $\mathrm{Ph} . \mathrm{D}$. student at the WindAM group at Chalmers University of Technology, Department of Energy and Environment, and Division of Electric Power Engineering. His research interests include wind power, reliability, maintenance and optimization.

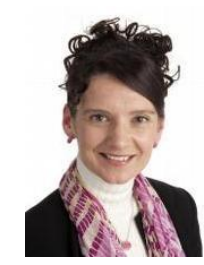

Lina Bertling (S'98, M'02, SM'08) holds the Chair of Professor in Sustainable Electric Power Systems and is the Head of the Division of Electric Power Engineering, at the Department of Energy and Environment, at Chalmers University of Technology, in Gothenburg, Sweden, since January 2009. She has been with Svenska Kraftnät, i.e. the Swedish Transmission Systems Operator during 20072009. She has been with the Royal Institute of Technology (KTH), School of Electrical Engineering, in Stockholm, during1997-2009, where she became Associate Professor in 2008, and finalized her Ph.D. in 2002 on reliability-centered maintenance for electric power distribution systems. She has been visiting researcher at the University of Saskatchewan during the spring semester 2000 , and a postdoctoral fellow at the University of Toronto, and associated with Kinectrics Inc. during 2002/2003. Dr. Bertling is the Chair of the Swedish PE/PEL Chapter, and the Chair of the IEEE PES Subcommittee on Risk, Reliability and Probability Applications (RRPA). She is a member of the Editorial board of the IEEE Transactions of Smart Grid. She was General Chair of the first IEEE PES Innovative Smart Grid Technologies (ISGT) Europe Conference, in Gothenburg, 2010. She is a member of the Swedish National Committee of Ciréd and the World Energy Council, and a member of Cigré. She is a member of the Scientific Board of the Swedish Civil Contingencies Agency (MSB) and a Board member of the Swedish Wind Power Technology Center hosted by Chalmers University of Technology. She has been appointed as a member of the advisory council of the Energy Markets Inspectorate. Her research interests include the evolution of the electric power systems into Smart Grid and the application of probabilistic methods for reliability analysis and maintenance management, e.g. within the Wind Power Asset Management (WindAM) group she leads at Chalmers. 